\title{
Quality Evaluation for Microcrystalline Silicon Thin-Film Solar Cells by Single-Layer Absorption
}

\author{
Sheng-Hui Chen, Ting-Wei Chang, and Hsuan-Wen Wang \\ Department of Optics and Photonics, National Central University, Chung-Li 320, Taiwan \\ Correspondence should be addressed to Sheng-Hui Chen, ericchen@dop.ncu.edu.tw
}

Received 30 June 2011; Accepted 15 November 2011

Academic Editor: Fabrice Gourbilleau

Copyright (c) 2012 Sheng-Hui Chen et al. This is an open access article distributed under the Creative Commons Attribution License, which permits unrestricted use, distribution, and reproduction in any medium, provided the original work is properly cited.

The absorption coefficient at $1.4 \mathrm{eV}$ is divided by the value at $0.9 \mathrm{eV}$ to obtain the factor used to judge the quality of $\mu \mathrm{c}-\mathrm{Si}: \mathrm{H}$. PV device performance can be predicted by multiplying $V_{\mathrm{oc}}$ with $I_{\mathrm{sc}}$ when using this layer as an intrinsic layer. The results show a good relationship between the quality factor and the product of open-circuit voltage and short-circuit current. However, the final efficiency is influenced by the identities of the interface in the multilayer structure.

\section{Introduction}

Hydrogenated silicon thin film is a potentially important material in the development of thin-film solar cells. Defect density in hydrogenated amorphous silicon (a-Si:H) or hydrogenated microcrystalline silicon $(\mu \mathrm{c}-\mathrm{Si}: \mathrm{H})$ thin film has been studied in the past years as an important measure of the material quality [1]. The dangling bond is the main type of defect in a-Si:H and $\mu \mathrm{c}-\mathrm{Si}: \mathrm{H}$ and will introduce defect states within the mobility gap. The defect density influences the carrier transport and is therefore crucial for photovoltaic devices.

Defect density in silicon thin film can be determined by the electron paramagnetic vesonance (EPR) which is the most direct method for defect measurement. However, this method is not sensitive for determining the defect density when their density in the film is low. Constant photocurrent measurement (CPM) $[2,3]$ is known to be a sensitive method for evaluating the bulk defect density from optical absorption. The low-energy photon absorption leads to carrier transitions from the forbidden-gap defect states to the conduction band. In amorphous silicon, the center of the Gaussian distribution defect is located at $\sim 1.2 \mathrm{eV}$ below the bottom of the edge of the conduction band in the distribution energy of the density of state (DOS) [1].
The absorption coefficient at $1.2 \mathrm{eV}$ photo energy is directly related to the defect density in a-Si: $\mathrm{H}$.

There exists a large variety of structural $\mu \mathrm{c}-\mathrm{Si}: \mathrm{H}$ compositions including amorphous silicon, crystalline silicon grains, grain boundaries, and voids. The absorption in $\mu \mathrm{c}-$ $\mathrm{Si}: \mathrm{H}$ is influenced not only by the amount of defects but also by the crystallization volume fraction. The absorption spectrum measured by CPM also contains information about the crystallinity at a photon energy of $1.4 \mathrm{eV}$ [4]. Klein et al. suggested that defects in $\mu \mathrm{c}-\mathrm{Si}: \mathrm{H}$ may contribute to the absorption peaks at or below $0.9 \mathrm{eV}$ [5]. However, in $\mu \mathrm{c}$ Si:H thin films, dangling bonds could exist in the amorphous phase or at the grain boundaries and even in the crystalline phase. There are still considerable debates about the meaning of the absorption coefficient at $0.9 \mathrm{eV}$.

In this study, $\mu \mathrm{c}-\mathrm{Si}: \mathrm{H}$ intrinsic layers and $\mu \mathrm{c}-\mathrm{Si}: \mathrm{H}$ thin film solar cells were fabricated by PECVD. The absorption coefficient $(\alpha)$ of the $\mu \mathrm{c}-\mathrm{Si}: \mathrm{H}$ thin film intrinsic layers was between 0.8 to $2.1 \mathrm{eV}$ as characterized by CPM. We confirmed that the absorption coefficient at a photon energy of $1.4 \mathrm{eV}$ increased with increasing crystallinity of $\mu \mathrm{c}-\mathrm{Si}: \mathrm{H}$. We also found that the absorption coefficient at a photon energy of $0.9 \mathrm{eV}$ decreased with increasing crystallinity, perhaps related to a reduction in the ratio of the amorphous phase in $\mu \mathrm{c}-\mathrm{Si}: \mathrm{H}$. The electrical properties of $\mu \mathrm{c}-\mathrm{Si}: \mathrm{H}$ thin 
films were also influenced by both the defect density and crystallization volume fraction [6]. From this, we found, for the first time, a linear relationship between the ratio of $\alpha$ $(1.4 \mathrm{eV}) / \alpha(0.9 \mathrm{eV})$ for $\mu \mathrm{c}-\mathrm{Si}: \mathrm{H}$ intrinsic layers, multiplied by the open-circuit voltage and short-circuit current $\left(V_{\mathrm{oc}} \times I_{\mathrm{sc}}\right)$ of the corresponding $\mu \mathrm{c}-\mathrm{Si}: \mathrm{H}$ thin-film solar cell. Hence the ratio of $\alpha(1.4 \mathrm{eV}) / \alpha(0.9 \mathrm{eV})$ of a $\mu \mathrm{c}-\mathrm{Si}: \mathrm{H}$ thin film becomes a factor for evaluating the quality of such films for photovoltaic applications.

\section{Experiments}

2.1. Preparation of Microcrystalline Silicon Thin Film. Microcrystalline silicon $(\mu \mathrm{c}-\mathrm{Si}: \mathrm{H})$ thin films were deposited on soda-lime glass substrates by plasma-enhanced chemical vapor deposition (PECVD) using silane with different hydrogen dilution ratios. Each of the $\mu \mathrm{c}-\mathrm{Si}: \mathrm{H}$ thin films has a different crystallization volume fraction. Film thickness is calculated from the interference pattern of the sample transmittance, which is controlled to be about $0.9 \mu \mathrm{m}$ for each sample. The crystalline volume fraction $X_{c}(\%)$ is calculated by the area ratio of the three Gaussian peaks in the Raman spectra at $480 \mathrm{~cm}^{-1}, 510 \mathrm{~cm}^{-1}$ and $520 \mathrm{~cm}^{-1}$ [7]. Single junction $\mu \mathrm{c}-\mathrm{Si}: \mathrm{H}$ thin-film solar cells were prepared by PECVD with different $X_{c}$ for the intrinsic layer. The absorption coefficient of the intrinsic layer was also characterized by CPM. Key parameters such as open-circuit voltage $\left(V_{\mathrm{oc}}\right)$, short-circuit current $\left(I_{\mathrm{sc}}\right)$, fill factor $(\mathrm{FF})$, and cell efficiency of those device were measured under standard test conditions.

2.2. Constant Photocurrent Measurement. A pair of parallel aluminum contacts was deposited on $\mu \mathrm{c}-\mathrm{Si}: \mathrm{H}$ thin films in order to perform constant photocurrent measurement. The contacts were $1 \mathrm{~cm}$ in length and spaced $0.1 \mathrm{~cm}$ apart. We use the transmittance type CPM (T-CPM) suggested by Sasaki et al. [8] to measure the absorption coefficient of $\mu \mathrm{c}-\mathrm{Si}: \mathrm{H}$ thin films where a constant voltage bias is applied on the $\mu \mathrm{c}-\mathrm{Si}: \mathrm{H}$ thin film to acquire the photocurrent under illumination. The photocurrent was collected by a computercontrolled Keithley 6485 electrometer. A monochromatic light beam illuminated the backside of the sample in order to avoid surface roughness-induced scattering. The photoconductivity can be expressed as

$$
\Delta \sigma=\Delta n q \mu
$$

where $\Delta n$ is the excess carrier density and $\mu$ is the electron mobility. In the steady state, the excess carrier density can be written as $\Delta n=G \tau$, where $\tau$ is the excess carrier lifetime and $G$ is the photoexcitation rate. The average photoexcitation rate can be also expressed as

$$
G=A \times \frac{\Phi}{d_{0}},
$$

where $d_{0}$ is the film thickness, $\Phi$ is the photon flux of incident light, and $A$ is the absorbance of the film. Due to fact that the detector is placed behind the sample in T-CPM, the signal received by the detector is proportional to the flux of the incident light multiplied by the transmittance:

$$
\text { Detector signal }=\Phi \times T \text {. }
$$

If we combine (1) and (2) and substitute the expression of photon flux of the incident light from (1) and (2), the detector signal can be expressed as:

$$
\text { Detector signal } \propto\left(\frac{T}{A}\right)\left(\frac{\Delta \sigma d_{0}}{q \mu \tau}\right) .
$$

By keeping the photocurrent constant, the quasi-Fermi level of the majority carriers is fixed. Assuming that the mobilitylifetime product is wavelength independent, we can obtain the relationship

$$
\frac{A}{T}=C_{\text {ref }}(\text { Detector signal })^{-1},
$$

where $C_{\text {ref }}$ is a calibration factor. The calibration factor is estimated by taking the ratio of detector signal with the sample $A / T$ obtained from the UV-Visible spectrometer at the photon energy of $1.9 \mathrm{eV}$. The value of the detector signal after calibration is then substituted into the RitterWeiser formula [9] to calculate the defect-related absorption coefficient

$$
\begin{aligned}
\alpha d_{0}=\ln \left(0 . 5 \left\{\left(1-R_{2}\right)\left(1+\frac{A}{T}\right)\right.\right. & \\
+ & {\left.\left.\left[\left(1-R_{2}\right)^{2}\left(1+\frac{A}{T}\right)^{2}+4 R_{2}\right]^{1 / 2}\right\}\right), }
\end{aligned}
$$

where $R_{2}$ is the reflectivity of the air-film interface, which is 0.36 for the case of backside illumination.

\section{Results and Discussion}

Figure 1 shows the Raman spectra of three kinds of $\mu \mathrm{c}$ Si:H thin films. The $X_{c}$ of these films are $41.2 \%, 55.7 \%$, and $63.5 \%$, respectively. The corresponding absorption coefficient of the $\mu \mathrm{c}-\mathrm{Si}: \mathrm{H}$ thin films is shown in Figure 2. We can see a conspicuous difference with the varying of the $X_{c}$ of the film. The characteristics of the absorption spectrum can be divided into three parts as follows.

3.1. Photon Energy Greater Than $1.8 \mathrm{eV}$. The absorption coefficient at a photon energy larger than $1.8 \mathrm{eV}$ showed an inverse proportionality to the crystallinity of the film. The $\mu \mathrm{c}-\mathrm{Si}: \mathrm{H}$ thin film is composed of amorphous tissue and small crystal grains as well as the grain boundaries. Because the absorption of amorphous silicon is larger than crystalline silicon, the absorption coefficient will tend to have amorphous features from the statistical point of view if the $X_{c}$ of the $\mu \mathrm{c}-\mathrm{Si}: \mathrm{H}$ thin film is reduced.

3.2. Photon Energy around $1.4 \mathrm{eV}$. The results show that the absorption coefficient around $1.4 \mathrm{eV}$ increased with $X_{c}$, 
TABLe 1: Performance of each $\mu \mathrm{c}$-Si:H thin film solar cell with different crystallinity $X_{c}(\%)$ in the intrinsic layer.

\begin{tabular}{lcccc}
\hline Solar cell parameters & $X_{c}=53.4 \%$ & $X_{c}=56.7 \%$ & $X_{c}=58.5 \%$ & \multicolumn{2}{c}{$X_{c}=60.8 \%$} & 0.484 \\
\hline$V_{\text {oc }}(V)$ & 0.533 & 0.510 & 0.502 & 19.314 \\
$J_{\text {sc }}\left(\mathrm{mA} / \mathrm{cm}^{2}\right)$ & 16.976 & 18.297 & 18.213 & 6.517 \\
FF $(\%)$ & 62.880 & 63.961 & 62.769 & 65.924 \\
Efficiency $(\%)$ & 5.685 & 5.967 & 5.740 & 6.165 \\
\hline
\end{tabular}

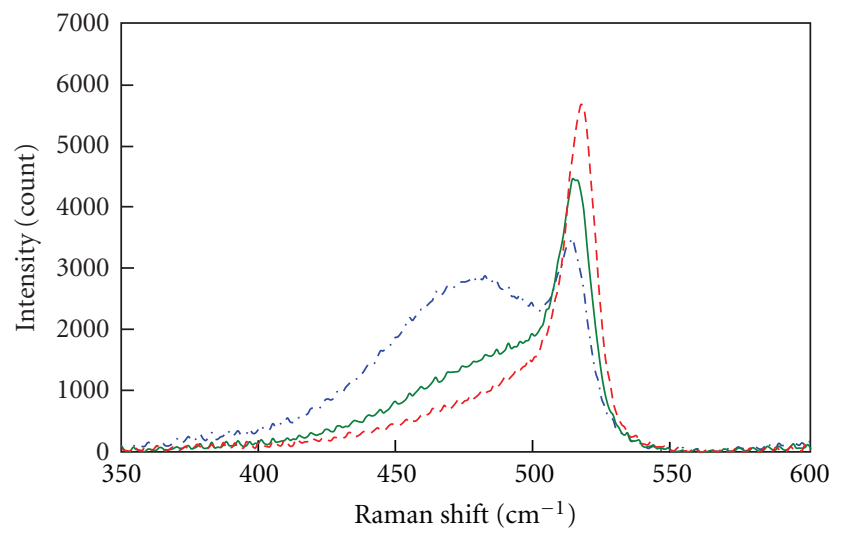

$$
\begin{aligned}
-\cdot-X_{c} & =41.2 \% \\
-X_{c} & =55.7 \% \\
---X_{c} & =64.7 \%
\end{aligned}
$$

FIGURE 1: Raman spectra of $\mu \mathrm{c}-\mathrm{Si}: \mathrm{H}$ thin films with different crystalline volume fractions.

which reflects the fact that the absorption coefficient around $1.4 \mathrm{eV}$ is dominated by the c-Si. The photon energy around $1.4 \mathrm{eV}$ is lower than the bandgap of a-Si and relates to the Urbach tail in the absorption coefficient diagram. However, a photon energy around $1.4 \mathrm{eV}$ can be strongly absorbed by $\mathrm{c}$-Si and excite the carriers from the valance band to the conduction band. Therefore, the absorption coefficient of c$\mathrm{Si}$ at $1.4 \mathrm{eV}$ is 3 orders of magnitude larger than that of a-Si, and dominate the absorption coefficient of $\mu \mathrm{c}-\mathrm{Si}: \mathrm{H}$ from the macroscopic point of view. This is in good agreement with the results proposed by Siebke et al. [4].

3.3. Photon Energy below $0.9 \mathrm{eV}$. The photon energy is not enough to make a band-to-band transition for both c-Si and a-Si, but it is enough to excite the carriers from the defect states to the conduction band. Previous studies have shown that the absorption is caused by a defect-related transition in the amorphous phase and in the crystalline grains [10]. Because $\mu \mathrm{c}-\mathrm{Si}: \mathrm{H}$ thin film is composed of a-Si and c-Si, the magnitude of the absorption coefficient at photon energies of $0.9 \mathrm{eV}$ indicates the number of defects of a $\mu \mathrm{c}-\mathrm{Si}: \mathrm{H}$ thin film [5]. In Figure 2 it can be seen that the absorption coefficient at $0.9 \mathrm{eV}$ decreases with increasing $X_{c}$. Although we cannot tell the number of grain boundaries in each sample simply from the value of $X_{c}$, we can speculate that most of the dangling bonds will be located in the amorphous

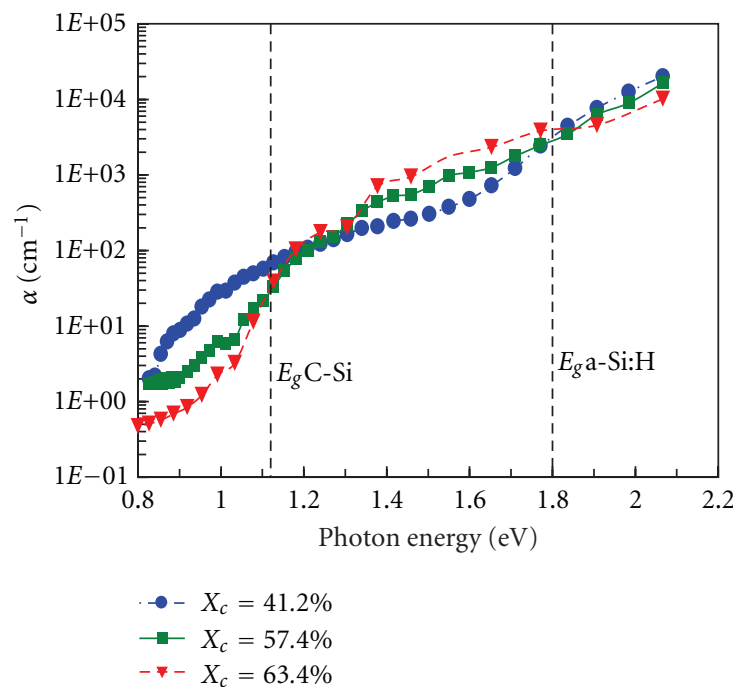

Figure 2: Absorption coefficients of $\mu \mathrm{c}-\mathrm{Si}: \mathrm{H}$ thin films with different crystalline volume fractions.

phase. Reduction of the volume fraction of the defect-rich amorphous phase could lead to a decrease in the defect concentration for a $\mu \mathrm{c}-\mathrm{Si}: \mathrm{H}$ thin film from the statistical point of view.

We can conclude from the above that the electricaldependent properties, such as the crystalline volume fraction and defect density of the $\mu \mathrm{c}-\mathrm{Si}: \mathrm{H}$ intrinsic layer, will be reflected in the absorption spectrum. The absorption spectrum of the $\mu \mathrm{c}-\mathrm{Si}: \mathrm{H}$ intrinsic layer might be associated with the $I-V$ characteristics of the $\mu \mathrm{c}-\mathrm{Si}: \mathrm{H}$ thin film solar cells having the same intrinsic layer. In this part of the experiments, we prepared $\mu \mathrm{c}$-Si:H intrinsic layers at different hydrogen dilution ratios by PECVD. The $X_{c}$ varied from $56.7 \%$ to $63.4 \%$. The absorption coefficient of these thin films was measured by CPM, and the results are shown in Figure 3.

P-I-N single junction $\mu c-S i: H$ thin-film solar cells with corresponding $\mu \mathrm{c}-\mathrm{Si}: \mathrm{H}$ intrinsic layer were also fabricated. The electrical properties such as the $V_{\mathrm{oc}}, I_{\mathrm{sc}}$, fill factor, and conversion efficiency were also examined under the standard test conditions. In Figure 3 we can see clearly that the absorption coefficient at $1.4 \mathrm{eV}$ is proportional to the crystalline volume fraction. The small difference in $X_{c}$ between each sample makes the trend of the absorption coefficient at $0.9 \mathrm{eV}$ appear blurry, but it does show a gradual decay with increasing $X_{c}$. The $I-V$ characteristics of the cells are listed in Table 1. We defined a "quality factor" by taking $\alpha$ 


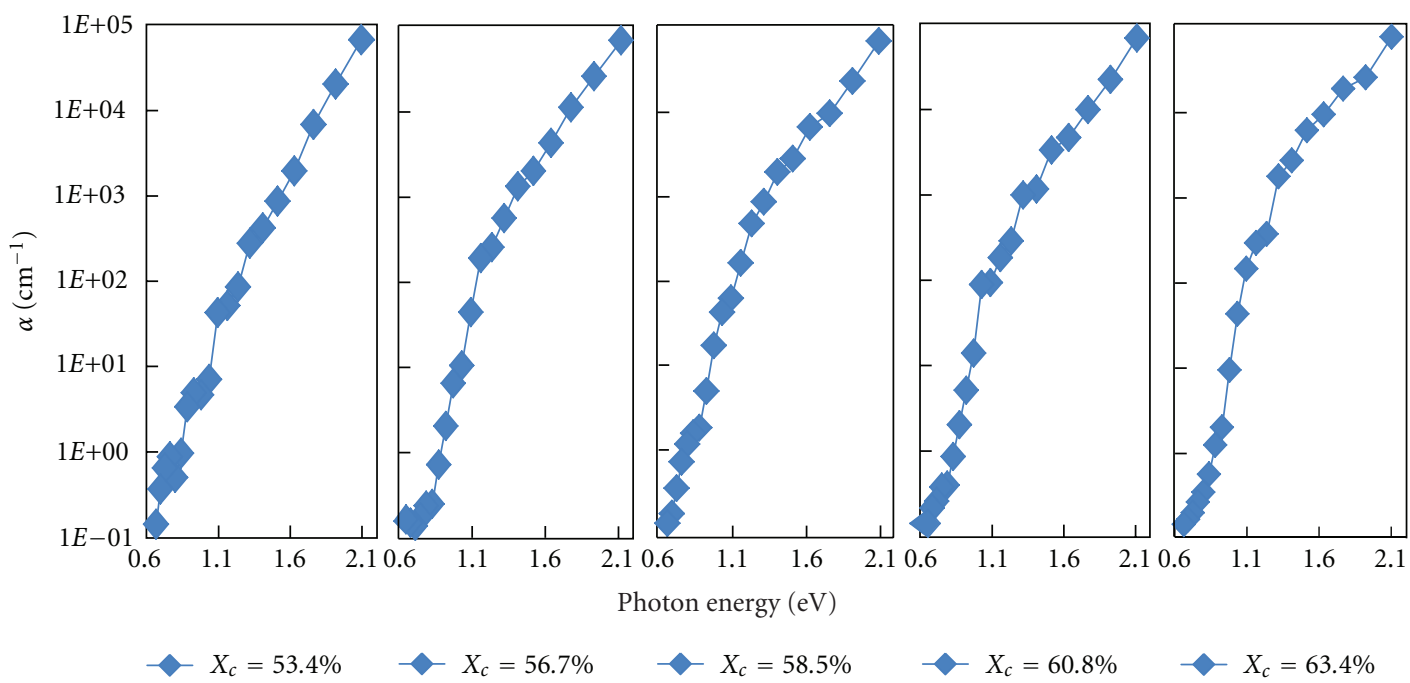

FIgURE 3: Absorption coefficients of $\mu \mathrm{c}-\mathrm{Si}: \mathrm{H}$ thin films for the corresponding cells.

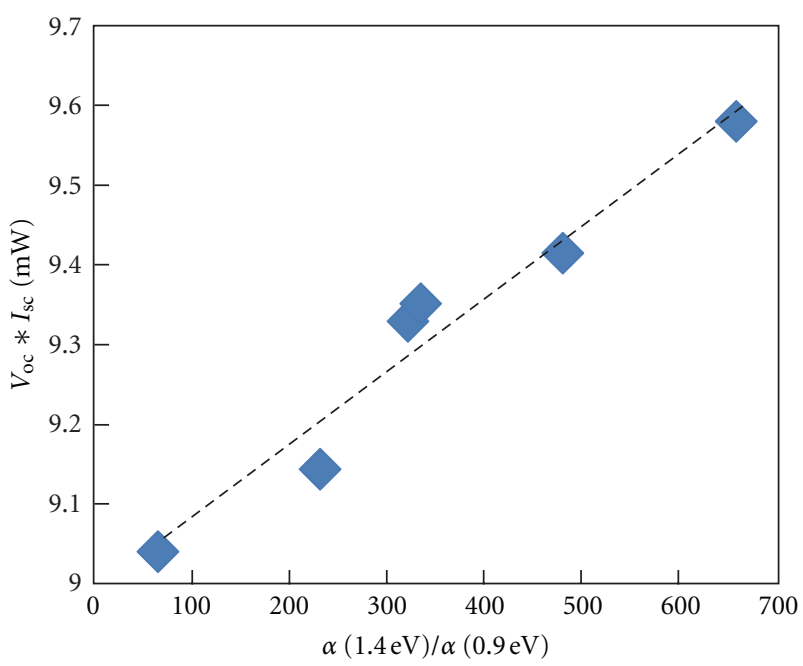

FIGURE 4: Relation between quality factor and $V_{\mathrm{oc}} * I_{\mathrm{sc}}$.

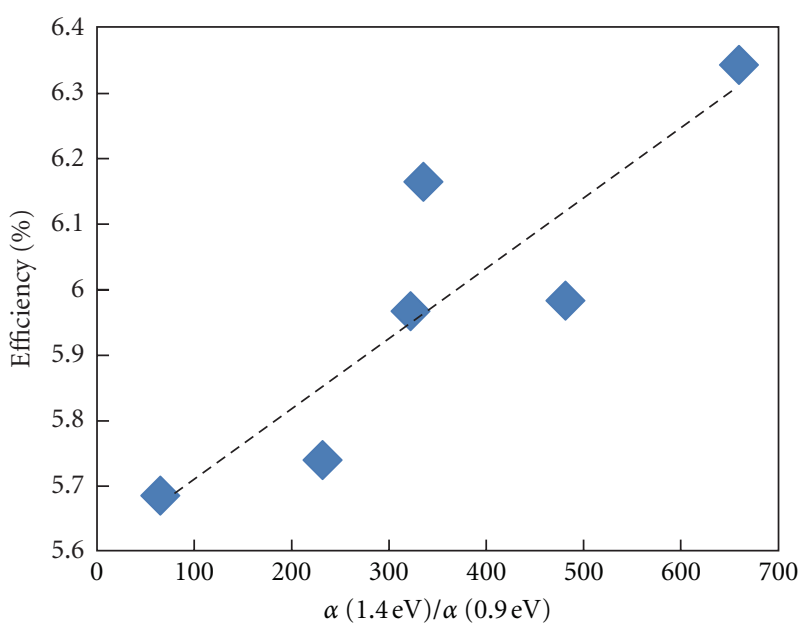

FIGURE 5: Relation between quality factor and cell efficiency.
$(1.4 \mathrm{eV}) / \alpha(0.9 \mathrm{eV})$ of the intrinsic layers shown in Figure 3. Surprisingly, we found a linear relationship between the "quality factor" and the $V_{\mathrm{oc}} \times I_{\mathrm{sc}}$ of the corresponding cells shown in Figure 4. For a single junction silicon thin film, the short-circuit current $\left(I_{\mathrm{sc}}\right)$ and open-circuit voltage $\left(V_{\mathrm{oc}}\right)$ were both influenced by the carrier mobility and carrier lifetime [11]. The $V_{\mathrm{oc}}$ is inversely proportional to the carrier lifetime, which is determined mainly by the defect density; $I_{\mathrm{sc}}$ is proportional to the carrier mobility, which is controlled by the crystalline volume fraction [12]. Since $\alpha(1.4 \mathrm{eV})$ is proportional to $X_{c}$ and $\alpha(0.9 \mathrm{eV})$ is proportional to the defect density, we can prove the linear relationship between the quality factor and $V_{\mathrm{oc}} \times I_{\mathrm{sc}}$ by the following formula:

$$
\frac{\alpha(1.4 \mathrm{eV})}{\alpha(0.9 \mathrm{eV})} \propto\left(\text { mobility } \times \frac{1}{\text { defect density }}\right) \propto \mathrm{I}_{\mathrm{sc}} \times V_{\mathrm{oc}} .
$$

Moreover, we cannot have such a good approximation if we plot the quality factor of the intrinsic layer and the efficiency of the corresponding cell as shown in Figure 5. The efficiency of the cell is determined by

$$
\eta=\frac{\mathrm{FF} \times I_{\mathrm{sc}} \times V_{\mathrm{oc}}}{P_{\mathrm{in}}}
$$

where $P_{\text {in }}$ and FF represent the input power and the fill factor of a cell. The fill factor is related to the series and shunt resistance of a device, which is not only determined by the quality of the intrinsic layer but also by the interface resistance between the silicon thin film and the electrodes [11]. Hence, the quality factor is only suitable for the indication of the $V_{\mathrm{oc}}$ and $I_{\mathrm{sc}}$ product rather than the device efficiency.

\section{Conclusion}

We have demonstrated that the characteristic $\mu \mathrm{c}-\mathrm{Si}: \mathrm{H}$ absorption of each wavelength will vary with differences in 
crystallinity. The absorption coefficient at a photoenergy of $1.4 \mathrm{eV}$ as measured by CPM was proportional to the crystallization volume fraction of $\mu \mathrm{c}-\mathrm{Si}: \mathrm{H}$. By dividing $\alpha$ $(1.4 \mathrm{eV})$ (proportional to the crystallinity) with $\alpha(0.9 \mathrm{eV})$ (proportional to the defect density), we can judge the quality of $\mu \mathrm{c}-\mathrm{Si}: \mathrm{H}$ and even predict the PV device performance, using the same $\mu \mathrm{c}-\mathrm{Si}: \mathrm{H}$ layer as in its intrinsic layer. However, the efficiency of microcrystalline solar cells is also influenced by the interface and other properties. The fill factor will affect the efficiency. The fill factor will affect the efficiency leading the error when we use predict the efficiency of microcrystalline solar cell by $\mu \mathrm{c}-\mathrm{Si}: \mathrm{H}$ quality factor.

\section{Acknowledgment}

The authors would like to thank the National Science Council of Taiwan for the financial supports of this research under Contract Nos. 100-2120-M-008-002, 100-2627-E-008-001 and 100-2221-E-008-111.

\section{References}

[1] R. A. Street, Hydrogenated Amorphous Silicon, Cambridge University Press, 1991.

[2] J. Kocka, M. Vanecek, and A. Triska, Advances in Amorphous Semiconductors: Amorphous Silicon and Related Material, World Scientific, 1989, Edited by H. Fritzsche.

[3] M. Vaněček, J. Kočka, J. Stuchlík, and A. Tříska, "Direct measurement of the gap states and band tail absorption by constant photocurrent method in amorphous silicon," Solid State Communications, vol. 39, no. 11, pp. 1199-1202, 1981.

[4] F. Siebke, S. Yata, Y. Hishikawa, and M. Tanaka, "Correlation between structure and optoelectronic properties of undoped microcrystalline silicon," Journal of Non-Crystalline Solids, vol. 227-230, no. 2, pp. 977-981, 1998.

[5] S. Klein, F. Finger, R. Carius, T. Dylla, and J. Klomfass, "Relationship between the optical absorption and the density of deep gap states in microcrystalline silicon," Journal of Applied Physics, vol. 102, no. 10, Article ID 103501, 2007.

[6] K. Yoshida, "Effective conductivity in association with structures of two-phase random composites," Philosophical Magazine B, vol. 53, no. 1, pp. 55-67, 1986.

[7] L. Houben, M. Luysberg, P. Hapke, R. Carius, F. Finger, and H. Wagner, "Structural properties of microcrystalline silicon in the transition from highly crystalline to amorphous growth," Philosophical Magazine A, vol. 77, no. 6, pp. 1447-1460, 1998.

[8] M. Sasaki, S. Okamoto, Y. Hishikawa, S. Tsuda, and S. Nakano, "Characterization of the defect density and band tail of an aSi:H i-layer for solar cells by improved CPM measurements," Solar Energy Materials and Solar Cells, vol. 34, no. 1-4, pp. 541-547, 1994.

[9] D. Ritter and K. Weiser, "Suppression of interference fringes in absorption measurements on thin films," Optics Communications, vol. 57, no. 5, pp. 336-338, 1986.

[10] T. Merdzhanova, R. Carius, S. Klein, F. Finger, and D. DimovaMalinovska, "Defect states in microcrystalline silicon probed by photoluminescence spectroscopy," Thin Solid Films, vol. 511-512, pp. 394-398, 2006.

[11] J. Nelson, The Physics of Solar Cells, Imperial College Press, 2003.

[12] S. O. Kasap, Principles of Electronic Materials and Devices, McGraw-Hill, 2005. 


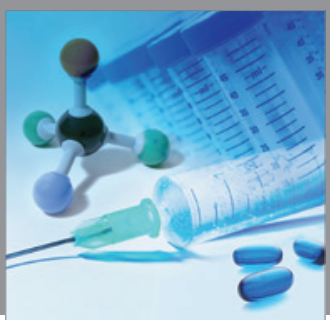

International Journal of

Medicinal Chemistry

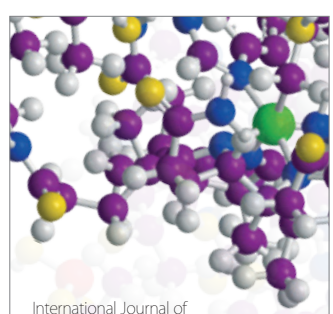

Carbohydrate Chemistry

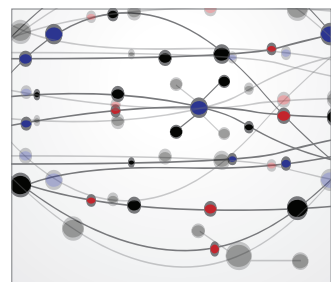

The Scientific World Journal
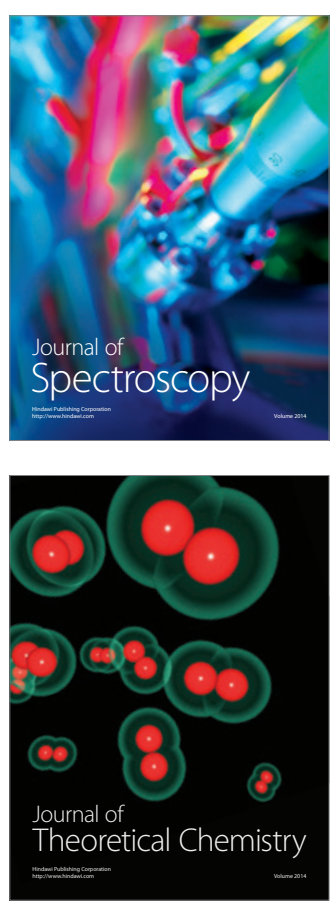
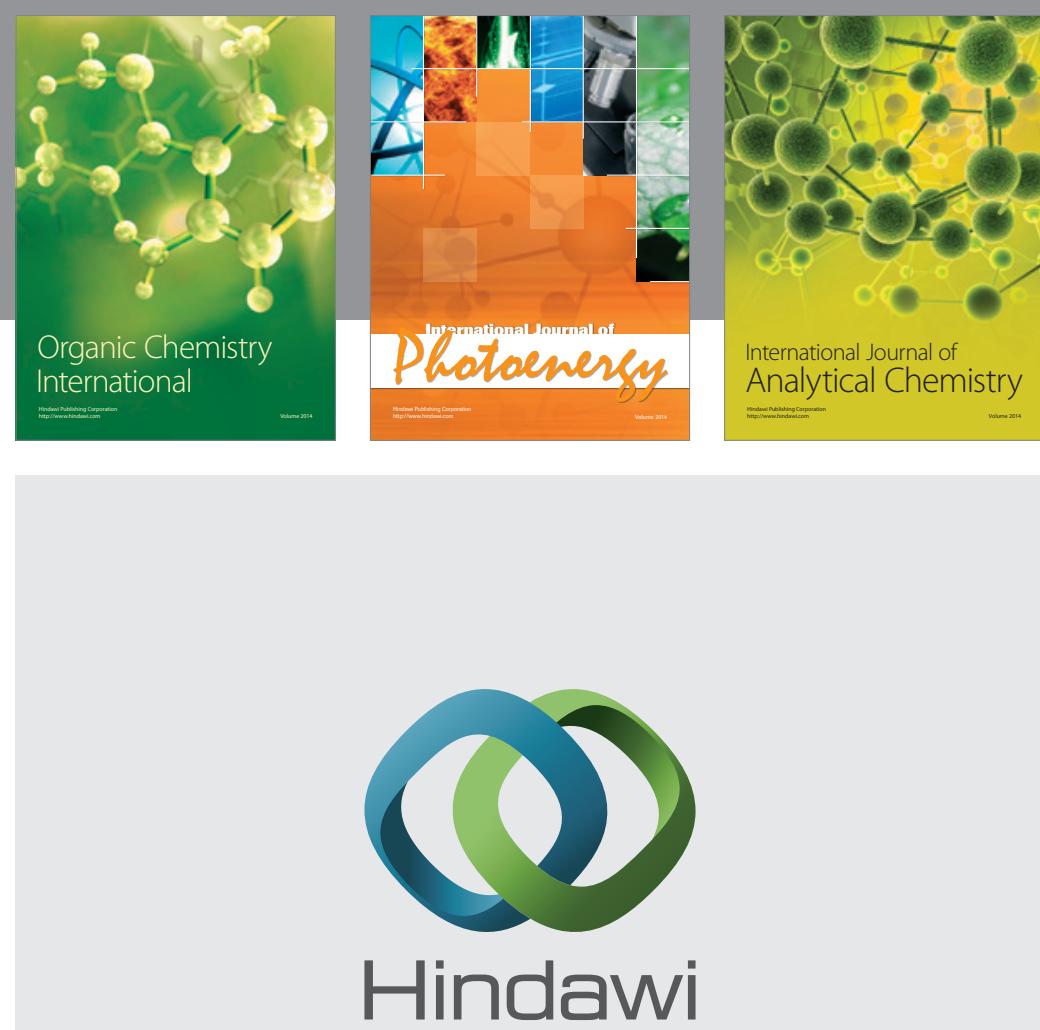

Submit your manuscripts at

http://www.hindawi.com
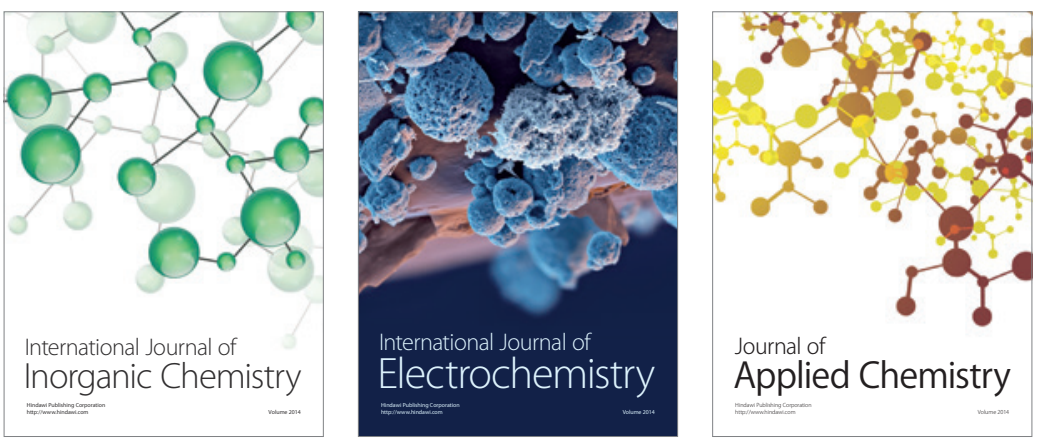

Journal of

Applied Chemistry
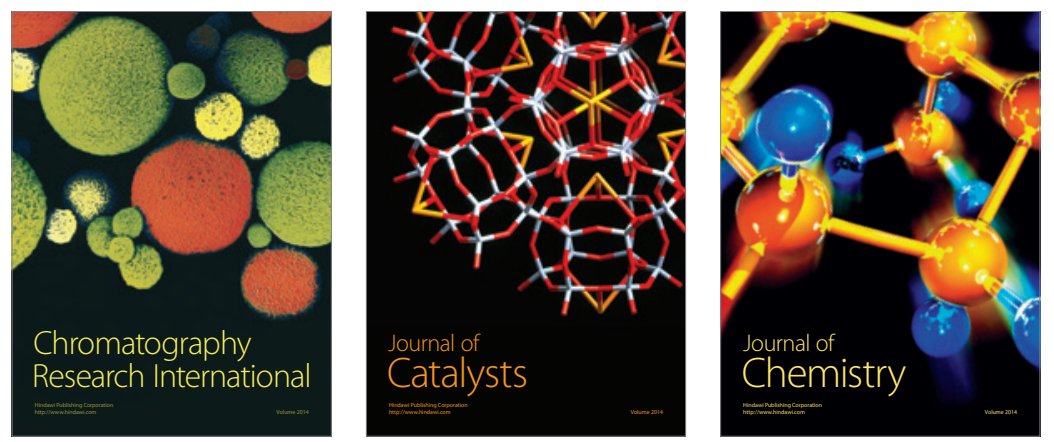
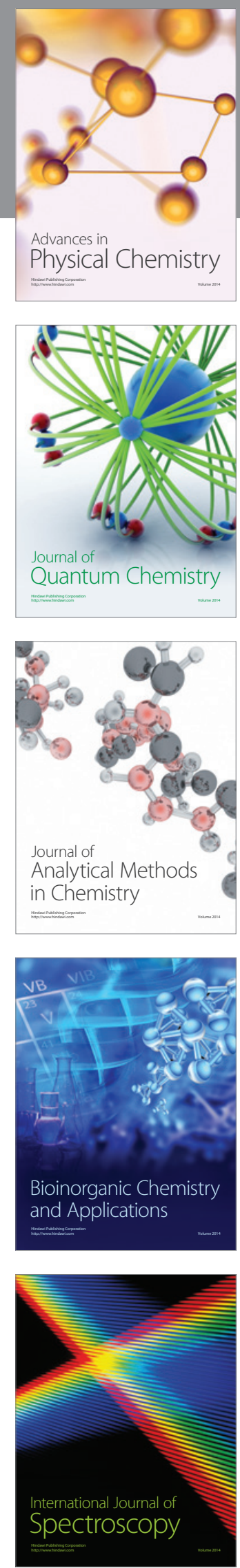